\title{
An Argument for Libertarian Free Will: Hard Choices Based on either Incomparable or Equally Persuasive Reasons
}

\author{
Randall S. Firestone \\ Department of Philosophy, El Camino College, Torrance, CA, USA \\ Email: Randyfirestone@verizon.net
}

How to cite this paper: Firestone, R. S. (2017). An Argument for Libertarian Free Will: Hard Choices Based on either Incomparable or Equally Persuasive Reasons. Open Journal of Philosophy, 7, 64-93. https://doi.org/10.4236/ojpp.2017.71005

Received: December 25, 2016

Accepted: January 21, 2017

Published: January 24, 2017

Copyright $\odot 2017$ by author and Scientific Research Publishing Inc. This work is licensed under the Creative Commons Attribution International License (CC BY 4.0).

http://creativecommons.org/licenses/by/4.0/

\begin{abstract}
This articles proposes that the best explanation for hard choices, which are choices made when there are either incomparable options or equally appealing options, is the presence of libertarian free will; and that the two main alternatives, determinism and random choice, do not provide us with very compelling explanations. In the case of determinism, this is because the reasons supporting each option do not dictate or necessitate that we choose that option, and therefore any decision is necessarily underdetermined by the reasons for each option. Random choice fares no better since any choice made when the options are incomparable or equally appealing is supported by reasons and therefore is not random at all. As such, we should believe in free will. The article further reviews some of the current neuroscientific studies and explains how they do not show the absence of free will. The paper further argues that science likely could never prove that we do not have free will since showing that any decision is reflected or caused by our brain neurons firing does not show that the ultimate decision was not arrived at after a free will consideration of the issues. Lastly, the article suggests that the best way to view free will is as an attribute and ability that is always present, and as such there is no such thing as partial free will. Accordingly, we are fully responsible for the decisions we make and the actions we take. However, external and internal influences, especially those that lurk in our subconscious and of which we are not consciously aware, do mitigate our blameworthiness and praiseworthiness for those decisions.
\end{abstract}

\section{Keywords}

Free Will, Libertarian Free Will, Partial Free Will, Determinism, Underdetermined, Responsibility, Blame, Studies on Free Will, Inference to the Best Explanation 


\section{Introduction}

Presently it is old school and unprogressive for intellectuals to believe in free will. By free will I mean it in the Libertarian sense of an "unconditional ability to do otherwise." Indeed, the majority of neuroscientists and philosophers have apparently abandoned the belief in this type of free will. ${ }^{2}$ This article will argue for the proposition that we should believe in libertarian free will-as it is the best explanation for certain decision-making situations. Specifically, I will argue that there are numerous situations we encounter in which we make hard choiceshard because the options present us with either competing incomparable reasons or equally weighted reasons, and further, that these hard choice situations are better explained as exercises in free will rather than as either determined or random decisions.

The type of free will I will be arguing for is the ordinary notion that nonphilosophers have of free will-philosophically known as libertarian free will or as Mark Balaguer puts it non-predetermined free will. It is the view that at least some conscious decisions a person or agent makes are decided by them and not by the many external and internal influences which act upon them. This type of free will is non-random in the sense that each decision unambiguously flows from the agent and does not just randomly occur for no reason at all and with no clear genesis or source. The agent is the author or source. It is the agent who chooses from among competing desires, instincts, habits, motivations, personal character and personality traits, and other mental states-even if that choice is to let one's instincts or desires run their course. This means as to the decision made, the agent could have chosen otherwise than they did. Although the decision can be and normally is influenced by both internal and external factors, these factors do not cause the actual decision that was made-the agent does. As Balaguer puts it, “(a) you did it, and (b) nothing made you do it.” (Balaguer, 2014: p. 129) ${ }^{3}$

This paper will expand on the work of Mark Balaguer as expressed in his book Free Will, and two of his articles on the subject, and specifically on his notion of

${ }^{1}$ I am using the term libertarian free will to distinguish it from the compatibilist notion of free will (also known as soft determinism) - which is merely a disguised determinism because the compatibilist does not believe we could ever do otherwise than we have done. Rather, the compatibilist asserts that we have free will by changing the definition of free will to meaning merely that there was no external forces that precluded our making a choice. For the compatibilist, if you do what you wanted to do, then you have free will, even if you could not have wanted to do otherwise than you did. The libertarian, on the other hand, believes your desires do not compel you to choose a certain way as you can choose contrary to your most entrenched desires and drives.

${ }^{2} \mathrm{~A}$ survey conducted in November 2009 by PhilPapers of 1,803 philosophy faculty members or PhDs and of 829 philosophy graduate students found that only $13.7 \%$ accepted or leaned toward libertarian free will. (PhilPapers, 2009)

${ }^{3} \mathrm{~A}$ similar although arguably somewhat limiting characterization of free will comes from Robert Kane. He defines free will as "the power to be the ultimate creator and sustainer of one's own ends or purposes." (Kane, 2016) A more robust definition comes from Eddy Nahmias, an associate professor at Georgia State University in both the Department of Philosophy and the Neuroscience Institute: "Many philosophers, including me, understand free will as a set of capacities for imagining future courses of action, deliberating about one's reasons for choosing them, planning one's actions in light of this deliberation and controlling actions in the face of competing desires." (Nahmias, 2011: p. 332) 
torn decisions, a term earlier used by the well-known libertarian philosopher Robert Kane. Professor Balaguer presents torn decisions as good candidates for examples of free will decisions. Torn decisions, which are decisions made when the alternatives appear to the decision-maker as substantially equal so that neither option seems better than the other, are one example of a hard choice case. I will present another example of a hard choice case, and as such another candidate for an example of the exercise of free will, one involving decisions when the choices, instead of being equally appealing, are incomparable so that one does not know which alternative is better or if the two options are equal. ${ }^{4}$

My conclusion, however, will go beyond Balaguer's since he argues that although there is presently no good reason to believe that we do not have free will, he believes that there is also no good reason to believe that we do have free will. He believes it is an unsettled empirical question. My position is that free will is the best explanation for one's decisions when they are faced with hard choices, and as such, not only are there good reasons to believe in free will, but we should believe in it since one generally should go with the best explanation. This is especially true when both of the other alternatives seem substantially less likely to be true, as I will argue is the case on the free will issue, and further, when the universal, daily, and strong experience of human beings is that we are the agents of our decisions. Accordingly, libertarianism is the most reasonable position in the free will debate.

Additionally, unlike Balaguer, I believe it is fair to place the burden of proof for this issue on the denier of free will because all of us have the strong and daily experience of making decisions where we could have chosen otherwise. ${ }^{5}$ That is, we have the feeling of agency in these decisions. The decisions we make do not feel forced upon us or in any sense inevitable, nor do they feel like random events that just happen to us. We have the strong experience that we make decisions. ${ }^{6}$ It seems only fair to place such a burden of proof on those people who wish to question a universal human experience. We should note that on numerous occasions scientists have has been able to overcome this burden of proof by producing convincing physical evidence. For example, scientists have been able

\footnotetext{
${ }^{4}$ Balaguer's basic definition of a torn decision does seem to encompass my example of incomparable choices, but his explanation of torn decisions seems to rule them out since he describes torn decisions as occurring when the "agent's reasons are neutral between a set of tied-for-best options." In the case of incomparable reasons the options cannot be assessed so the decision-maker is unable to conclude that the options are tied for best. (See Balaguer, 2004: p. 384) In any event, Balaguer does not spend time specifically addressing the situation when the options are incomparable, so at the worst I am further developing and explaining his own idea of a torn decision.

${ }^{5}$ Balaguer thinks that the question of free will is an extremely difficult empirical question dealing with causation (or lack of causation) of certain neural events, and since we are presently substantially ignorant on this topic, we should not presume one way or the other. (See Balaguer, 2014: pp. 121-125) Even if Balaguer is correct in this regard, he leaves us in the rather unattractive default position of taking no position at all-both for the present and into a probably distant and indefinite future.

${ }^{6}$ To place the burden on the denier of free will is merely to require the denier to (1) produce some evidence indicating that we do not possess free will, and (2) produce enough evidence so that when all the evidence presented by both sides is assessed, the evidence is more likely to support the position indicating that free will is an illusion.
} 
to overcome the sensory and universal views of a flat earth and of the sun orbiting the earth. However, I will argue that not only have neuroscientists failed to do this to support the view that we do not have free will, but I will explain why I believe that this likely could never be done in a scientifically compelling or persuasive manner. ${ }^{7}$

Finally, it seems to be fashionable and common among those who believe that we probably or may have free will, including Balaguer, to take the position that free will can be partial or limited. I will argue against this viewpoint and attempt to show why we either have free will or we do not have it, and if we have it then it is always with us, meaning we always fully have it. When it comes to human decision-making, there is no such thing as a partial determinism and a corresponding partial free will. Free will is not limited in degree. If we have free will, then in every conscious decision we exercise that free will-sometimes by actively choosing among alternatives, and sometimes by merely tacitly choosing to not stop ourselves from going along with our most dominant instincts, emotions, desires, or first reactions. Since free will is an attribute and ability we possess, it is always fully there and operational, or so I will argue.

\section{Hard Choices Occur When the Options Are Either of Equal Weight or Are Incomparable}

Ruth Chang, who has written extensively on the literature concerning incomparable options and incommensurable values in a somewhat different context, ${ }^{8}$ provides us with a definition of a hard choice: "In the most general terms, hard choices are ones in which reasons "run out": they fail, in some sense, to determine what you should do." (Chang, 2012: p. 107) She presents the following three situations which could present a paradigmatic hard choice for an individual:

You are a single parent unhappy in your current job and have just received your dream job offer in a different city. But your young children are leading happy, fulfilled lives which would be less good were you to move the family. Should you take the job?

You have decided to spend your Saturdays giving back to the community. You can help organize for your favorite candidate's re-election campaign or mentor a disadvantaged child in your neighborhood. How should you spend your Saturdays?

You're getting a bonus in your paycheck and could buy a new car or donate the funds to Oxfam. What should you do? (Chang, 2012: pp. 106-107)

Of course, for many people these situations would not constitute a hard

\footnotetext{
${ }^{7} \mathrm{I}$ am making my argument for the presence of free will based on a materialist or physicalist conception of the world. In other words, my argument views free will as part of the physical world. If, on the other hand, one's belief in free will is based on the assumption that free will is immaterial and comes from an immaterial soul, then the burden of proof should shift to them because there is no direct (or arguably even indirect or circumstantial) evidence supporting the existence of anything that is non-physical or immaterial.

${ }^{8}$ Chang's concern is that of practical reason, not free will.
} 
choice because one option would be more appealing. However, these situations could present hard choices to the decision maker in two different ways: First, for some people, they would present choices of equal weight, or second, for other people they could be incomparable in that the reasons to choose any given option would be neither better, worse, nor of equal weight when compared to the reasons supporting the alternative choice or option.

The first type of hard choice is explored in Professor Balaguer's 2004 article on free will, $A$ Coherent, Naturalistic, and Plausible Formulation of Libertarian Free Will. In this article Balaguer presents his argument for the position that humans may have free will when faced with a torn decision. He explains as follows:

A torn decision is a decision in which the person in question (a) has reasons for two or more options and feels torn as to which set of reasons is strongest,, i.e., has no conscious belief as to which option is best, given her reasons; and (b) decides without resolving this conflict-i.e., the person has the experience of "just choosing". (Balaguer, 2004: p. 382)

A torn decision occurs when the actual decision is made when the person is still torn-when the agent makes a decision but has not concluded that one set of reasons outweigh the competing set of reasons. Balaguer thinks this usually happens several times a day. He explains why we find ourselves in the position of having to make torn decisions by taking the example of a decision made at an ice cream shop:

And the reason you would want to choose while still feeling torn should be obvious: if you got to the front of the line, and everyone was waiting, it would make a lot more sense to make a torn decision-that is, to just choose-than it would be to keep on deliberating, or to just stand there until it became clear to you which flavor you wanted. (Balaguer, 2014: p. 64)

In his 2004 article, Professor Balaguer gives us two other examples of torn decisions. The first is Ralph's decision to either move to New York or stay in his life-long residence in North Carolina. Ralph would stay in North Carolina because he has a solid job position as an assistant manager and a probable future opportunity to become manager at the same company, plus he has an opportunity to marry his local sweetheart, but New York presents employment opportunities not available in North Carolina, such as professional football and acting, opportunities which could lead to greater fame and fortune than would be possible if he stays in North Carolina. Ralph makes the decision to move, but never actually decides that is the best option. He "just decided to go." (Balaguer, 2004: p. 383)

The second example is whether Jane should order a fruit plate or tiramisu for dessert. She believes the tiramisu will taste better, but knows that the fruit plate is healthier. When the waiter comes and asks for her dessert choice, she decides to go with the tiramisu-not because she believes it is the better option, but rather because she must make a choice so makes it without ever deciding that one 
option was the best.

Balaguer argues that these decisions are good candidates as examples of free will, although he admits that although they seem to be exercises of our free will, they may actually be determined. I agree with Balaguer that they are good candidates for free will, and I will argue that in fact such situations should persuade us to believe in free will.

Additionally, I want to present an at least equally appealing candidate for free will, namely, one involving situations where the choice to be made is based on competing options which are in some important sense incomparable for the decision-maker. ${ }^{9}$

In order to do this, we must first explore the similar ideas of incomparability and incommensurability, and how those two terms relate to each other. We might start off by stating that most thinkers on this subject believe that two items are incomparable if one is neither better than, worse than, nor equally as good (or bad) as the other. This has been referred to as the Trichotomy Thesis-a thesis which I will assume to be true for our purposes. (See Chang, 2012: p. 111)

Chang gives us a simple example of a hard choice involving a possible incomparable decision: Suppose you had a choice between rocky road ice cream and mango sorbet, and you were making your judgment solely on taste. Chang continues: "Tasting each dessert in turn, you might come to the following judgment: Neither tastes better to you right now. After all, they taste very different, and while both would be delicious, they would be delicious in rather different ways. You might also judge that they aren't equally tasty." (Chang, 2012: p. 109) The point Chang is making is that it appears that you are having so much difficulty comparing the two deserts that they have become incomparable to you regarding what she calls the "covering consideration" of taste. You cannot reach a conclusion whether one alternative is better, worse, or the same as the other. You only know that they are very different-both tasty, but also very different in a way that makes the comparison impossible for you. We should note that this comparison might be easy for many if not most other people, but not for you.

Incommensurability, on the other hand, has been defined in various ways, but the most basic definition is that items are incommensurable if there is no common standard by which to judge them. They simply lack a common measure. We can see that if they lack a common standard by which to judge them, then they will often be incomparable-after all, it becomes very difficult to compare if there is no standard on which to base the comparison. So, for example, friend-

\footnotetext{
9I seems that Kane used the term "torn decision" in a somewhat more general way than does Balaguer so that it is closer to Chang's term "hard choice." This paper will use the term torn decision to apply only to the cases that Balaguer limits it to, namely, situations when the alternatives appear equally appealing or persuasive to the decision-maker. Kane's idea of a torn decision is explained as follows: Now I believe these undetermined self-forming actions or SFAs occur at those difficult times of life when we are torn between competing visions of what we should do or become. Perhaps we are torn between doing the moral thing or acting from ambition, or between powerful present desires and long term goals, or we are faced with a difficult task for which we have aversions... There is tension and uncertainty in our minds about what to do at such times. (Kane, 2016)
} 
ship and money are usually considered to be incomparable, and this is due, at least in part, to the fact that they are so different that no common standard from which to rank or rate them seems possible. ${ }^{10}$

To contrast Balaguer's example of comparable and equally appealing or persuasive options with my example of incomparable options, we can look at Balaguer's elaboration of his definition of a torn decision:

In any torn decision, the agent's reasons are neutral between a set of tiedfor-best options. Thus, the reasons-based probabilities of the various live options are equal (or at least roughly equal). (Balaguer, 2004: p. 384)

In the case when options are incomparable, we do not assess the options as being "tied-for-best," nor are the probabilities for the choices we make "roughly equal." Instead, in many cases what I believe actually occurs is that our mind reaches an impasse precisely because it cannot compare the reasons due to their incomparability. As such, there really are not any "tied-for-best options" because we never conclude or believe it is a tie between roughly equally appealing alternatives. We do not know if they are equal, and never conclude that they are. On the contrary, we just feel stuck, and do not know how to tackle the dilemma or choice. We do not know how to compare the choices. We do not know if the reasons are equal or equally appealing, and hence we are having difficulty in making a decision. This is especially true when the outcome of one or more options is difficult to assess, as is especially true when our choices involve highly unpredictable future outcomes. We do not know how the future will work out, and we realize we do not know. In a sense, oftentimes we are not sure what we are comparing due to the great uncertainty of the outcomes involved in each choice. Indeed, competing incomparable reasons means we are not neutral between "tied-for-best options;" rather, we are perplexed, confused, muddled, and stuck because we do not know whether the competing options are tied or not.

Along these same lines, when we are in the position of deciding between competing incomparable reasons, we are unable to assess that "the reasonsbased probabilities of the various live options are equal (or at least roughly equal)" as Balaguer asserts is done when making a torn decision. Again, we cannot assess the probabilities because it is often the case that they involve unknown futures. Given the identical situation 20 times, on any given occasion it is un-

\footnotetext{
${ }^{10}$ However, as Chang has pointed out, there are exceptions where a lack of a common standard will not render the options incomparable. She explains, for example, that even if the abstract values of justice and mercy are incommensurable as they lack a standard from which we could judge one to be superior to the other in all cases, they are comparable in certain contexts: Justice may be better than mercy in promoting a stable and legitimate government, while mercy may be better than justice in developing one's kindness. (I have slightly changed Chang's last comparison.) Chang also concludes that while not all incommensurable values make the choices between them incomparable, if two choices are incomparable they must also be incommensurable in that there cannot be a common standard by which to judge them. (Chang, 2014) I think Chang is wrong regarding this second point. Options can have a common standard by which to be judged and thus be commensurable, but still be incomparable due to the two other factors I mention later in this paper: Complexity regarding all the variables that need to be considered, and Future Unknowability, which together can preclude the ability to engage in any meaningful comparison.
} 
known and unpredictable which choice you will make because you are stuck between unknowable alternative outcomes. After the fact (hindsight), the percentages of the decisions made in identical circumstances may turn out 50/50 the first ten times, and 70/30 the next ten times. Indeed, the first ten times the choice was made may turn out to be very different than the next 10 times. Going into the choice there was no probability at all, just indecision until a decision is made. When we make the decision between incomparable options, there is no way to say that the probabilities were equal because the incomparability means that each time the decision is being made there just isn't any probability of which option would actually be chosen on that occasion.

Let me approach this idea of incomparable reasons for our choices with an example that will be familiar to many of us. When having a difficult time making a decision, have you ever compiled a list of reasons for and against each choice? Did it help you make your decision? I have made such lists on several occasions, and it has never helped me at all. What I saw when I made the list was that there were good reasons supporting each possible decision, and in effect I saw why I was unable to come to a decision. Making the list brought me no closer to deciding which of those reasons were strongest-because the reasons on one side were not stronger than the reasons on the other side, nor could I assess them as equal-they were just different. They were independent considerations that were not comparable in a fashion that aided me in making my decision.

I understand now that when faced with competing considerations of different kinds, there is no way to make the best decision because there is no surefire way or standard to weight certain considerations over others, or to know what the future outcomes of those decisions will be. There often is just no right or best decision, but nonetheless there are good reasons for whichever decision is made, and of course, the same is true for the alternatives which were not chosen. In fact, some people realize this and routinely after making a choice continue to fret that things may have worked out better if they had chosen one of the other alternatives-and of course they are right. Their choice was made in a world with imperfect knowledge about the future, often with many people and variables to consider, and at times with no standard from which to judge.

As Balaguer has pointed out, torn decisions between equally competing alternatives seem to be a regular part of our lives-whether it is in choosing which item to order off of the dinner menu, or whether to take that potentially promising but risky job offer or not. Similarly, I believe that decisions made when the reasons supporting each option are incomparable are just as common, and probably more so.

But why? Why does our mind quite regularly reach an impasse and view the options as incomparable?

I believe that there are three factors which are often present in situations when we have difficulty deciding because we feel that the two or more options are incomparable:

1) Complexity: Often there are so many people or variables to consider that 
our mind feels overwhelmed and so we cannot adequately process or compare the options.

2) Future Unknowability: Often in considering the best option we must make predictions about what will happen in the future if we choose that option, but the future is unknown, and in many situations very hard to predict. When we realize this in a given situation, our minds often reach an impasse and cannot decide which option is better.

3) Incommensurability: We have no standard to evaluate one set of values or goals as more important than another, so have no basis to compare the options. This is especially true when comparing lives. Even if we knew how each life would turn out under each option, comparing two different lives (which would result in our becoming two different people) would often be incomparable.

Oftentimes, all three factors are present-although any one of them may be sufficient to make the options incomparable to the decision-maker. We will apply these three factors in the next section.

\section{Free Will Is the Best Explanation for Hard Choices}

Let us examine another scenario-similar to Balaguer's example of Ralph's dilemma of whether or not to move to a new city based on a job opportunityusing the actual facts and decision my father had to make when I turned 13 years old. Suppose you have an interesting and secure job that pays you fairly well but not great, and you are married with three children who are 7, 11 and 13 years old. You have lived in Chicago your whole life and have close relationships with your extended family and friends-all of whom live in the Chicago area. However, the likelihood of an opportunity to go into top management at your present company is quite low. You have kept your eyes open for a better job opportunity, and eventually have found and been offered a much higher paying job to become a Vice President of a growing corporation in Los Angeles. You would be able to live your dream of becoming a corporate executive in charge of managing many people and products, and this job could well be a stepping stone to even higher and more prominent jobs. You now have to make a decision on whether to take this new job. Should you?

On the one hand, you have a very good situation right now. To move to a new city would take you away from your family and friends, and would disrupt the lives of your wife and children. Your children would be put into new schools, and all of you would have to make new friends. On the other hand, if the new job were to work out, you would be able to provide a better lifestyle and opportunities for your family. You would also have a more challenging and rewarding job.

However, although you think you will get along with your new boss and colleagues, you cannot be sure. In fact, you have no way to know if things will work out at the new job or in your new home in Los Angeles. There is no way to really know unless and until you take the new job. Of course, if you stay in Chicago you likewise cannot be sure what the future will hold. Maybe you will eventually 
be given presently unforeseen opportunities and be able to go into management at your present company or at another one in the Chicago area. Or maybe your present company will undergo changes so your job will become less secure, or you will get a new boss with whom you do not get along.

You are faced with future uncertainty no matter which option you choose, and you feel you cannot assess which option is best. You cannot adequately evaluate the choices, at least in part, because they are based on a future which is uncertain. Will your children have problems making friends at their new school, or will they be able to make very close friends? If one of your children has trouble getting along with some kids in your present neighborhood, would a new school and city provide a better opportunity for him or her to flourish? Even if one child would benefit from the move to Los Angeles, will either of your other children have problems adjusting to your new home in a new city with new friends to make? What about your wife-how would the move affect the quality of her life?

Your head is spinning with all of the possibilities, and you do not know which decision to make, but eventually you make one-not deciding or believing it is necessarily the best decision, but it is a decision based on good reasons since there are good reasons for either choice. It is your decision based on reasons you have considered, but you realize that it may not be the better decision.

We can see that the three factors which make choices incomparable are present here.

1) Complexity: There are several people to consider, and many aspects of each of their lives to consider.

2) Future Unknowability: With either choice, we do not know how the lives of any of our family members will turn out.

3) Incommensurability: Comparing the quality and worth of lives would seem to be virtually impossible as there are no obvious standards or norms that would not be exceedingly broad and general and therefore of little practical value. Let us say I valued health, love, friendships, success, wealth, autonomy, and power. These are quite general, and certainly many possible lives would include each of these to some extent. How would you compare one life with more fame, power, and better health to another life with more friendships and wealth? For many people, they would find themselves unable to assess and compare. Elizabeth Anderson explains as follows:

Consider Sarah, who must choose between two ways of life... One is secure, content, and parochial, focused on the cultivation of fulfilling and loving relationships among a small circle of friends and family. The other sacrifices lasting relationships with intimates for the sake of an outstanding career in ballet, which offers excitement, glamour, significant contributions to world culture, and broader knowledge of the world. Each way of life is good in its own way and defective in others. Suppose Sarah has equal prospects of leading either life successfully. I claim that consequentialism cannot plausibly argue that the value of Sarah's leading one way of life is commensurable 
with the value of her leading the other... We have no grounds for claiming that one way of life is impersonally better overall than the other. Nor are they judged equal in value. (Anderson, 1993: p. 57)

So in the assessment of which life would actually be best for you and your family members, we could easily find ourselves in the situation where our mind has hit an impasse. Whatever choice you make may turn out better for some of your family members, and worse for other family members. How can you weigh and compare the benefits for some to the detriments for others? How can you assess the degrees of benefit and detriment to each family member? You realize that you cannot adequately do so, but you will make your decision nonetheless. You break the impasse, but without having a compelling reason to choose one option over the other. When you make your decision, you have not decided if the options are equal or not, or that one is better than the other. You have simply chosen.

Let us say you decide to move, as my dad did so decide. What is the best explanation for your decision? It seems there are three possibilities here-as there is in any conscious decision which we make:

1) Free Will

You exercised your free will and made a choice. You could have chosen otherwise than you did. Your genetics, your past experiences and actions, and the situations you have found yourself in and find yourself in now do not necessitate or dictate your decision. Any decision you make is for reasons you have considered and chosen to follow, but you could have chosen not to take this job and move to California at that time.

2) Random

You do not have free will, but your choice was not determined; rather, it was random. By this I mean that you just randomly chose one of the optionsmeaning you chose both without respect to any reasons for your choice and without consideration of any of the reasons. You simply had two or more choices and chose one of them. Your choice was arbitrary. As Balaguer puts it, "if, on the other hand, your decision wasn't caused by anything, then it just happened. In other words, it happened randomly." (Balaguer, 2014: pp. 41-42)

Perhaps some impulsive decisions actually are random and not based on the consideration of any reasons at all. This would be an empirical question whether we ever do this. It may indeed be true that we make some decisions without considering the reasons, and only after the decision might we rationalize our decision by finding or creating reasons which we attribute to the decision-makingreasons that we had not even considered before making the decision.

The renowned French existentialist philosopher Maurice Merleau-Ponty supported this possibility. He proposed that sometimes we make a decision and only deliberate afterward to find the motives or reasons that support that decision.

What misleads us on this is that we often look for freedom in the voluntary deliberation which examines one motive after another and seems to opt for the weightiest or most convincing. In reality the deliberation follows the 
decision, and it is my secret decision which brings motives to light, for it would be difficult to conceive what the force of a motive might be in the absence of a decision which it confirms or to which it runs counter. When I have abandoned a project, the motives which I thought held me to it suddenly lose their force and collapse. (emphasis added) (Merleau-Ponty, 1945:

pp. 278-279)

So it remains a possibility that at least some of the time, we choose for no particular reason at all and in an arbitrary fashion, and only later may search for motives and reasons behind our decisions. However, it seems unlikely that this happens very often since in most cases we seem to make our choice for reasons which we have, however briefly, considered.

We need to distinguish two types of randomness in our choices. Balaguer sets forth the situation where you have reasons for each choice, but because the choices are roughly of equal weight, you choose between them without having a good or compelling reason to choose one option over another. In such a case, we could say that your ultimate choice had a kind of randomness or arbitrariness in that there were no good reasons to make one choice over the other. We are in a similar situation when it comes to incomparable choices. However, as Balaguer points out, these situations are not random in the important and relevant sense for free will. If there were good or compelling reasons to make each choice, and if we noticed and considered those reasons, then our decision was for those reasons and not random at all. We made the decision, even though that decision was arbitrary or random in a secondary way in that we never decide that one of the last two options is actually better. In these cases, it is still the agent who chooses between the choices.

Indeed, when choices are incomparable or assessed as equal in weight- even if there is no good reason to make one choice over another-that choice appears to be a good candidate to be viewed as a free will choice since we make our choice for one or more good reasons. It is a free will decision because we are the one who makes the choice-even though there is no compelling reason to make one choice over the other. ${ }^{11}$

So for our purposes now, I am limiting the idea of a "random" decision to one where a choice is made without acknowledging, noticing, and/or considering any of the reasons. You just make a choice-as when you act impulsively with no aforethought.

3) Determinism

You do not have free will. Your choice was determined from the time of the Big Bang because we live in a deterministic world of blind physical forces. Your

\footnotetext{
${ }^{11}$ Balaguer spends a considerable amount of time explaining how free will is compatible with this secondary type of randomness where we have good reasons for choosing each alternative, but when one set of reasons do not outweigh the alternative set of reasons. He explains as follows: If Sandy has to choose between $A$ and $B$, and if her reasons don't pick out a unique best option, it simply doesn't follow that for this reason alone, she can't make a decision at all, or that when a decision does happen, it isn't Sandy who makes and controls the decision. Intuitively, the notions of authorship and control seem to allow for a random selection here, so long as it is Sandy who makes the random selection and not something external to her. (Balaguer, 2004: p. 392)
} 
led him to the following conclusion regarding the issue of whether the brain, which is the source of our thoughts and decision-making, is a product of deterministic causality or not:

There isn't a shred of evidence given for the claim that all of the causation involved in the brain is deterministic causation ... Current neuroscientific theory treats a number of different neural processes probabilistically, and any decent textbook on neuroscience will point this out. For instance, synaptic transmission and spike firing are both treated probabilistically. (Balaguer, 2009: p. 10)

Balaguer supports his point by quoting from the textbook Theoretical Neuroscience which states that synaptic transmitter release is "spontaneous" and "neuronal responses are typically treated statistically or probabilistically." (See Balaguer, 2009: p. 10, and Dayan \& Abbot, 2001)

Second, determinism seems to ask us to swallow an awful lot without either overwhelming or even strongly compelling evidence. If determinism is true, then everything that has ever happened in human history had to have happened as it did, and every thought of every person who ever lived had to occur at the exact time and place as it did. In other words, it had to happen that Joan of Arc would have lived when she lived and took the actions that she took and played a role in the exact deaths that she did, and helped exactly those people whom she helped. There had to have been a Hitler who was responsible for the deaths of tens of millions of innocent people, and also an Einstein who discovered what he discovered at the exact moment he made each discovery. In fact, it had to be that you would be born at the exact place and time that you were, and you had to have had every accident, experience, emotion, and triumph that you have had, and you had to have read these words at this precise moment and, what's more, you had to have the very thoughts you are having at this moment. It could not be otherwise. Nothing in history could have been otherwise than it has been. Moreover, this is true for the last 14 or so billion years that our universe has existed, and if we had perfect knowledge we would have been able to accurately predict everything that has ever occurred and been thought. Wow! That is a lot to assume without proof-and yet there is no scientific evidence to prove this deterministic claim. ${ }^{12}$

Even putting aside these considerations, our hard choice example of whether

\footnotetext{
${ }^{12}$ Although I think there are some competent responses, Alan Gewirth advanced an interesting additional argument as to why we should not accept the determinists' account of our decisions-proposing that the determinists' position is bordering on being self-contradictory: [ $T$ ] he determinist thesis is unable to account for itself, and indeed it is at odds with itself. If the thesis is true, then the intellectual or cognitive operations of its upholders, including their choice or decision to maintain the thesis, far from proceeding in terms of independent careful consideration of reasons and arguments, are themselves only the effects of inexorable forces beyond the upholders control. But if this is so, why should the thesis that results from these operations be accepted as valid and true? If, on the other hand, the thesis does indeed rest on the intellectual examination of reasons and arguments and a considered choice based thereon, then the thesis is false as a universal account of human behaviors. (Gewirth, 1978: p. 36)
} 
to move or not points us away from determinism. In hard choices, the reasons alone are not able to dictate what our choice will be. Put another way, if the options are incomparable, the ultimate decision we make seems necessarily underdetermined by the reasons for making each choice. Once we know and list all of the reasons for each possible decision, we still do not know what to do-we still do not see or believe that one choice is clearly better based on its supporting reasons. And this belief may be based on a good reason-in cases similar to our moving scenario, there just is no such a thing as a better or right choice. The alternatives do not present us with overwhelming and winning reasons that necessitate any given decision. If not, then how could our decision be determined?

Indeed, if the reasons do not have the power to present us with an option which we had to have chosen, then any choice we make must be underdetermined by the reasons or options. It would seem that we will have to choose from the competing reasons even though those reasons do not necessitate that we choose them as they are not clearly better or superior than the reasons supporting the competing alternative choices, nor even clearly equal. ${ }^{13}$

Random: Now consider the alternative of pure randomness. If my choice is not determined, then it is either random or was made by the exercise of my free will. But randomness does not seem to fit here since I have reasons for whichever choice I make, and I do not make the decision for no reason at all. In fact, that is why the decision is a hard choice-I can't make up my mind after considering the reasons. I feel stuck precisely because I have considered reasons for making each choice, and find the reasons on each side appealing. Indeed, the hard choice is hard because we are considering the reasons and find them to be incomparable. So randomness as we defined it (as a choice made without consideration of any reasons) does not seem to be a suitable explanation for hard choice situations. The choices or decisions made cannot be random since it is the very consideration of the reasons which causes the difficulty in making the decision, and whatever decision is made has been made for the reasons already considered.

In other words, if I have considered the reasons, then it is a good candidate for being a free will choice, and even though I have no compelling reasons to pick one alternative over the other, it is still I who am making the choice, and doing so for reasons which I have considered. After all, in most cases there are many alternatives which I do not even consider because I do not believe that the reasons supporting those choices are very good.

Free Will: We are left with the only plausible explanation for our ultimate choice as a product of our free will. We have reasons for whichever choice we ultimately choose so the choice is not random. Additionally, since the reasons for each option are incomparable, there is no one best set of reasons that would necessitate that we choose that set over any one of the alternative sets of reasons.

\footnotetext{
${ }^{13}$ Someone might respond that reasons are not the only relevant factor regarding the choices we make; rather, don't our drives, instincts, and desires provide us with the basis of our actions? In my view, our drives, instincts, and desires are reasons for choosing a certain way. In a sense they just are our reasons. Indeed, we have many different types of motivations for our actions, and those motivations provide us with reasons to choose.
} 
As such, the ultimate decision cannot have been necessitated and determined. The fact seems to be that there is no one right or best or even better choicethere is just our choice for our reasons. Our ultimate choice will be chosen for our reasons, and those reasons may be very good reasons, but we could have chosen otherwise since there are also reasons for the other choice or choices which may also be very good. This is the best explanation for our ultimate decision-the exercise of our free will.

Indeed, just because you do something based on your desires doesn't mean you could not have done otherwise. Why? Because we have numerous desires, inclinations, drives, and motivations that push and pull us in different directions. We have free will if we are the one who is choosing between them-and due to the numerous people and variables often present (Complexity), uncertainity about the future (Future Unknowability), and the lack of a common standard by which to compare, weigh, and judge these factors (Incommensurability), in many situations there could not possibly be one right decision, i.e., there is no way that one decision could be determined or necessitated by the past.

Note how this analysis applies equally well to Balaguer's scenario involving options of equal weight. In both cases, our decision is made for the reasons we considered so is not random, and there is no one best option-they are either equally good or compelling, or they are incomparable. Whatever choice is made is underdetermined by the reasons for making each choice. As such, in both types of hard choices, it is not only reasonable to believe in free will, but actually it is the rational belief as it is the best explanation of our decisions made when options are either equal in weight or incomparable.

This conclusion is further supported by an additional consideration: We experience that we have free will and could choose otherwise than our past would indicate. In other words, we seem to have introspective awareness of choosing one thing over another in a way that's not determined by our desires, drives, preferences, benefits, perceived advantages, beliefs, and other motivating reasons for our views and actions. We feel as if those factors influence our decisionsoften to a substantial degree, but not that they make or determine our decisions for us. ${ }^{14}$

Now admittedly this is not the most attractive example of a free will decision because there is a type of randomness or arbitrariness since we have no good reason or reasons to choose one of our options over another. However, we have had to use the hard choice scenarios in order to rule out determinism. It is only in the hard choice scenarios when one choice does not clearly outweigh the other that we can be fairly confident that determinism is not present-because in those situations (from the perspective of the agent who is deciding) the ultimate decision is underdetermined by the reasons. Once we establish that these situations are probable examples of free will, we can then recognize that free will de-

\footnotetext{
${ }^{14} \mathrm{I}$ am not here including the common argument that it appears that we are morally responsible for our actions, and moral responsibility requires free will, so therefore we must have free will. It seems to me that although this is a common philosophical way to argue for positions, it is really circular in that you are assuming what you must prove or at least argue for.
} 
cisions are made all the time in other contexts, including in the many situations where we find one set of influences or reasons to be the most compelling or appealing to us.

In his gracious review of this paper, Professor Balaguer has suggested to me that I have not given a fair shake to the deterministic and random alternatives because I have ignored the possibility that all of our decisions, including our hard choice decisions, might be made below the level of our consciousness. He proposes that when we face a hard choice decision, our brain could engage in a "neural coin tossing event" of which we are unaware, and the result of the "coin toss" could be either determined or random. In essence, he is arguing that all decisions could be made by subconscious or non-conscious bodily/neural processes, and as such there would be no room for free will because free will requires a conscious decision-making process.

While I cannot definitively rule out this possibility, there appears little reason to believe it to be true because it would render much (or possibly all) of our conscious thoughts to be useless and with no purpose-in other words, superfluous. Our consciousness would have no role in causing or even contributing to our decisions, and would seem to be pointless and powerless. Given that the functioning of our brains require a substantial amount of the calories our body needs (approximately 20\%), and given that it is likely that the conscious portions of the brain use a not-insubstantial amount of those calories, it seems unlikely from an evolutionary standpoint that consciousness would exist if it did not play an important role in our decision-making and therefore our survival.

We should notice that the architecture or structure of the typical decision involves conscious thoughts at every stage of the decision-making process-each of which would be unnecessary according to the suggestion made by Balaguer: We are conscious there is a choice to be made, then we consciously look for alternatives from which to choose, then we consciously look at the pros and cons of each alternative, then we consciously compare the alternatives, then we consciously decide on and choose one of the alternatives, then we consciously have thoughts, feelings and/or reactions regarding our decisions, then at times we consciously regret our initial decision, and then on occasion we consciously change our decision. Regarding hard choices, we must add that we have a conscious thought that the alternative options are either of equal weight or are incomparable, and then we make our conscious choice. But according to the scenario that our decisions are subconscious or below the level of our consciousness and that we therefore do not possess free will, all (or at least many) of these conscious thoughts had no purpose at all. They were unnecessary. There was no reason to have them. All the conscious effort and conscious emotional reactions during and after the decision-making process were unneeded. All of the mental energy and food that were needed to fuel those conscious thoughts were not required since we did not need those conscious thoughts. But if this were so, it seems that most or all of our conscious thoughts would have vanished long ago by way of the evolutionary disadvantages in having to find more food to support 
conscious thoughts which were actually unneeded and useless.

Eddy Nahmias agrees that if all decisions were formed from unconscious or subconscious decision making, then consciousness would be pointless, which seems contradictory to how evolution works.

It would mean that whatever processes in the brain are involved in conscious deliberation and self-control-and the substantial energy these processes use-were as useless as our appendix, that they evolved only to observe what we do after the fact, rather than to improve our decision making and behavior. (Nahmias, 2011: pp. 335-336)

One reply to my argument might be that a subconscious neural coin toss saves energy compared to a stressed-out deliberation, so isn't this more likely? This argument, I think, is actually close to being self-refuting. We know that we have stressful and complex conscious deliberations, and we know that we need food to produce the energy for those conscious thoughts. If our subconsciousness just spins out a decision, it is difficult to make sense of our phenomenal experience of the time, effort, and struggle that are involved in our making hard choices. Why would we have any consciousness regarding our decisions? This seems unexplainable when we posit that our hard choices are made by a subconscious neural coin toss.

Indeed, while it is theoretically possible that each step of our decision-making, including the ultimate decision, is composed of only subconscious or non-conscious thoughts or brain processes of which we are unaware at the time and of which we only later become consciously aware, it seems that the much greater likelihood is that our conscious thoughts during the decision-making process serve some purpose or purposes that impact the decisions which we make. To assert that all of our decisions are made subconsciously or below the conscious level is to assume what the determinist or "randomist" must prove or at least show is likely. Balaguer's suggestion asserts that determinism or randomness may be true and this is how it could be true (i.e., solely through neural processes and subconscious thoughts of which we are unaware), but without any real basis to believe it is actually so.

\section{Scientific Research Has Not and Arguably Cannot Refute Free Will}

Neuroscientists and philosophers often cite brain scan studies to support the proposition that humans beings do not have free will. They argue that our decisions are determined by neural processes outside of our conscious control. Specifically, they claim that unconscious brain processes precede our conscious decision, so our decision was already made for us before we consciously reached our conclusion. Put another way, conscious decisions are caused by unconscious events of which we are both unaware and are out of our control, and because these unconscious events occur before we consciously make our choice then we could not have free will. The choice or decision was already made for us. 
For example, Libet (1983) asked people to flex their right wrists whenever they wanted. He concluded that our decisions are made by our brain activity, technically known as "the readiness potential," a split second before we are aware or conscious of the decision. In another study Soon, Brass, Heinze, \& Haynes (2008), by looking at brain scans, were able to predict up to 10 seconds beforehand and with $60 \%$ accuracy which of two buttons a person would push. And a similar experiment by Fried, Mukamel, and Kreiman (2011) using implanted electrodes claimed an $80 \%$ accuracy rate in prediction based on brain activity 700 milliseconds before the person becomes aware of the decision already made.

Alfred Mele, Professor of Philosophy at Florida State University and past director of the Big Questions in Free Will Project, has pointed out why these studies are not convincing. (Mele, 2013) ${ }^{15}$ First, all of the studies suffer from the problem that the experiments involved very simple and unimportant decisions to which the participants would have been indifferent and which did not involve any reasoning and debating before the ultimate choice was made. For example, Libet's study which involved flexing of the wrist hardly seems like the proper subject matter to test free will. Instead of a basic action of no importance, we would want a study involving a more difficult and important decision with alternatives which require deliberation and the weighing of competing and incomparable reasons, preferably with both short-term and long-term consequences. Mele sums up this objection:

I have already observed that in these studies, there is never a reason to prefer the decided upon option to other relevant options and vice versa. This normally is not the case when people are making moral decisions. In typical cases of moral decision making, pros and cons are weighed... it is rash to assume that what happens in situations featuring indifference is also what happens in situations in which unsettledness about what to do leads to careful, extensive, conscious reasoning about what to do. (Mele, 2013: pp. 5, 7)

Second, since the authors of the Soon and Fried studies could not predict one's actions with $100 \%$ accuracy, we might conclude that their studies support the presence of free will, not of determinism. In fact, it seems that if there are brain neurons firing and those firings only produce a specific decision $60 \%$ of the time, we could conclude that those firings were not the actual decision at all, but rather were only a preliminary contemplation about an alternative or option that was being considered, or a very preliminary decision which was still being considered and questioned and was often reversed.

Furthermore, several recent studies have cast doubt on these earlier experiments. For example, a study by Schultze-Kraft (2015) concluded that the readiness potential can actually be overruled by the thinker up to a mere 200 milliseconds before the action is taken. Thus, one can reverse their earlier "decision" a mere fraction of a second before they take action. Here is an excerpt from that

\footnotetext{
${ }^{15}$ Balaguer also sets forth significant limitations and problems with the first two studies. (Balaguer,
} 2014: pp. 96-120; Balaguer, 2009: pp. 16-17) 
study:

In humans, spontaneous movements are often preceded by early brain signals. One such signal is the readiness potential (RP) that gradually arises within the last second preceding a movement... Our data suggest that the subjects can still veto a movement even after the onset of RP. Cancellation of movements was possible if stop signals occurred earlier than $200 \mathrm{~ms}$ before movement onset, thus constituting a point of no return. (SchultzeKraft, 2015)

In the study's press release, one of the lead researchers, Dr. John-Dylan Haynes, explained the significance of this research on the issue of free will:

A person's decisions are not at the mercy of unconscious and early brain waves. They are able to actively intervene in the decision-making process and interrupt a movement. Previously people have used the preparatory brain signals to argue against free will. Our study now shows that the freedom is much less limited than previously thought. (Reported by Jarrett, 2015)

Nahmias likewise concludes that the neuroscientific research does not provide evidence which precludes free will.

However, the existing evidence does not support the conclusion that free will is an illusion. First of all, it does not show that a decision has been made before people are aware of having made it. It simply finds discernable patterns of neural activity that precede decisions. (Nahmias, 2011: p. 334)

In actuality, I do not think any of these studies is or could be determinative on this issue, and in fact they are actually largely irrelevant on the issue of free will. At some point we would expect a decision to be registered in our brains. Neuroscience has shown us that our thoughts are dependent on our brains. ${ }^{16}$ It follows from this that our thoughts can be characterized as either the firing of brain neurons (full reductionism) or part of the same physical causal process as the brain neuron firings. So even if and when we will be able to look at the brain and see that a decision has been made, this does not defeat the view that we have free will. The free will, if it exists, would be present in the earlier deliberative thought process which will likewise be exhibited in our brains. We have free will if we are able to consider the alternatives and make a choice that is not determined by antecedent events. The fact that our decision is reflected in our brains does not defeat the possibility that we exercised free will to come to that decision. As stated by Mele, "Elsewhere, I have argued that even if our consciousness of decision making were always to lag a bit behind decision-making, that fact would not constitute a serious obstacle to free will." (Mele, 2013: p. 8)

\footnotetext{
${ }^{16}$ This is demonstrated by the fact that if we injure or have degeneration to certain parts of the brain we are unable to have certain types of thoughts. For example, if we injure some parts of the brain we will not be able to engage in moral decision making, and if we develop Alzheimer's Disease or Dementia then certain memories are lost to us.
} 
In other words, even if there is a time lag between unconscious brain events that represent our decision and our delayed corresponding conscious decisions, the unconscious brain processes are part of the same physical process. A thought just is a brain neuron firing. Balaguer explains it this way: "You have to say that the conscious decision just is the neural event. There aren't two different things here; there are just two different ways of describing a single event." (Balaguer, 2014: p. 57)

As such, the experiments of Libet, Soon, and Fried in no way show that we do not have free will, nor could they ever show as such. Put another way, looking inside the brain will not be able to resolve the issue of whether we have free will. The issue here is whether the brain neurons which fired and represent the ultimate decision did so after a free-will deliberation. Brain scans can detect our brain activity and our debating thoughts, but cannot resolve the issue of whether we can act contrary to the influences and directions that our genetics and environment are pushing us toward.

Indeed, I do not see how brain scans could ever show whether or not we have free will. Although it is true that whether we have free will is an empirical question, I do not see how we could ever test it. We can see brain neurons firing, and one day may be able to show what thought that corresponds to, but whether that thought was free or determined seems to be beyond our ability to test and therefore to know. One would have to show that at some earlier point the final neuron-firing decision had to have been made, but I do not see that ever happening-especially in view of the most recent research that shows we can change our minds a split second before the ultimate decision is made. ${ }^{17}$

\footnotetext{
${ }^{17}$ I admit that I haven't totally ruled out the possibility of empirical evidence settling the issue. Although it is a possibility, I do not believe it very likely we will be able to do so because even if we can match up each group of brain neurons firing to specific deliberations, reasons, and torn decisions, I do not know how we could be sure of the source of those brain neurons firing-whether the sources were determined or a part of our free will. A related issue involves how to understand and sufficiently describe the physical processes involved in free will, and how free will could have materialized or orginated. Presently this cannot be adequately explained because our theories of consciousness are far from complete. My own view is that free will is an emergent brain property. Similar to how life emerged from dead matter, and consciousness emerged once life developed a certain degree of complexity, I believe that free will emerged when consciousness developed a further degree of complexity. The free will allows us to overrule our instincts and genetic programming in a way that potentially enhances our survival, and operates very differently than both dead matter and plant life which may well be fully subject to deterministic forces. This is in keeping with modern scientific ideas that there seems to be different levels of reality which operate in different ways, and some of those levels may be determined while others may not be. For example, there may be indeterminism at the subatomic or quantum level, determinism for ("dead") matter and energy at the macro level which humans experience, and indeterminism at the level of human consciousness and decision-making by the exercise of free will. This point is put nicely by George Musser who quotes Christian List, a philosopher at the London School of Economics and Political Science: "If you have determinism at one particular level, it is fully compatible with indeterminism, both at higher levels and at lower levels." The atoms in our brain can behave in a completely deterministic way while still giving us freedom of action because atoms and agency operate on different levels... Individual atoms are completely inanimate, yet enormous masses of them can live and breathe. "Anything to do with agents, their intentional states, their decisions and choices. none of this features in the conceptual repertoire of fundamental physics, but that doesn't mean those phenomena are not real," List observes. "It just means that those are very much higher level phenomena." (Musser, 2015: pp. 90, 93)
} 


\section{Free Will Does Not Come in Degrees, although Blameworthiness Does}

It has become rather fashionable for those who believe we do or may have free will to conclude that free will comes in degrees, or is partial, or is not always present. For example, Eddie Nahmias argues as follow:

It is true that we are often influenced unknowingly by subtle features of our environment and by emotional and cognitive biases. Until we understand them, we are not free to try to counteract them. This is one reason I think we have less free will than many people tend to believe. (Nahmias, 2015: p. 78)

Similarly, Balaguer states that as follows:

There can be different degrees of causal determination... At one end of the spectrum, which option is chosen is wholly undetermined... At the other end of the spectrum, which option is chosen is causally determined by prior events together with causal laws. And in between, there is a continuum of possible cases... in connection with those in between cases, we can say that which option is chosen is partially determined-or equivalently, partially undetermined. (Balaguer, 2009: p. 5)

It seems to me to view free will as partial or limited is misguided. If we have free will, then we do not have it partially. If we can say "no" to our influences then we have the ability to do so in all circumstances, even if we are unlikely to do so when those influences are quite strong, or those influences are confined to our subconscious. Nahmias writes above that "we are often influenced unknowingly by subtle features of our environment and by emotional and cognitive biases." This is undoubtedly true, but an influence is not a necessity, and if we have free will then we have the ability to make a choice that is contrary to even the unknown influences, i.e., we have the ability to make a conscious decision to take our lives in a direction away from those influences-an ability that does not disappear just because those influences may be strong or even unrecognized by us. $^{18}$

It is important to distinguish the presence of free will from the exercise of free will. I view free will as an attribute that human beings possess, and as such, we always have it. However, we don't always exercise it. For example, if a doctor hits our knee to test our reflexes, we do not exercise our free will ability when our lower leg involuntarily moves forward. We certainly still had our free will, but

\footnotetext{
${ }^{18}$ We should note (following the vein of thought put forth by Ludwig Wittgenstein, Bertrand Russell, and A.J. Ayer) that this is arguably a linguistic issue, and not a true philosophical issue. In other words, Balaguer, Nahmias, and I may have the same basic understanding of the situation, but are disagreeing on how to best label it-meaning it is not a true philosophical issue to which we could obtain evidence that would help us make the decision between our competing perspectives. In spite of this, I do think it is more fruitful to view free will as an ability or attribute that is part of the human makeup and thus is always present and always utilized when we make conscious decisions. Influences, even ones of which we are not conscious, no matter how strong they are, do not negate that ability.
} 
we had no opportunity to exercise it. However, when we make conscious decisions, we always are exercising our free will because we have the power or ability to choose otherwise than our genetics and our past might indicate. Let's differentiate our actions into four categories:

1) Involuntary actions or reactions where we had no opportunity to make a conscious decision.

2) Conscious decisions that are made in accordance with our straightforward or uncontested desires, values, motivations, and other influences.

3) Conscious decisions where we have good reasons for each option, but that we do feel one set of reasons outweigh the competing set of reasons.

4) Conscious decisions when faced with hard choices due to conflicting equal or incomparable desires, values, motivations, and other influences.

In all four categories, we possess free will. In the first situation, we had no opportunity to exercise it. In the second category, we might have had little reason to notice it if we just went along with our dominant desires and motivations. In the third category, we are aware of exercising our free will. In the last category, we are most aware of exercising our free will since we are looking at reasons on both sides and are having a difficult time deciding.

We should note that in the last three cases we may well not recognize all the things which may be influencing us, such as implicit or unrecognized racism or sexism. Could we not then say that when the influences strongly move us toward a particular choice, especially when a substantial portion of those influences are in our subconscious and not consciously recognized by us, that we have a partial loss of our free will? I do not think this is the best approach or perspective. Since we have the ability to choose contrary to the most dominant influences, even unconscious ones, we have free will, and our free will is fully there and fully operable.

Nahmias, and others like him, seem to confuse blameworthiness and perhaps responsibility with free will ability. The many strong influences in our lives, both those of which we have a clear awareness and those which influence us unknowingly, do not negate our free will, which is our ability to choose from among numerous alternatives, although they arguably do relieve us of a certain degree of blameworthiness and/or responsibility.

Jean-Paul Sartre believed that the many influences on us, including those unknown, unconscious, or unnoticed, were merely part of the situation we encounter when we make our decisions. The situation contributes to our decision, as does our free will which acts upon the situation. Sartre explains as follows: "The situation... is an ambiguous phenomenon in which it is impossible for the for-itself (human beings) to distinguish the contribution of freedom from that of the brute existent." (Sartre, 1943: p. 241) For Sartre, the situation includes not only the circumstances you encounter, but also your past experiences, your talents, your character traits, your personality, your instincts and drives, your desires, and both your conscious and unconscious motivations. Even though the situation contributes to our decision, the situation in no way limits our free will. 
In other words, both the situation we find ourselves in, which might be determined for us in many respects, and our decision, which Sartre believed was not determined, play a role in our decision making, but that does not mean that our will was not fully free. On the contrary, the situation, which includes all of the external and internal influences on us, is the canvass upon which our free will acts.

Thus we begin to catch a glimpse of the paradox of freedom; there is freedom only in a situation, and there is a situation only through freedom. Human-reality everywhere encounters resistance and obstacles which it has not created, but these resistances and obstacles have meaning only in and through the free choice which human reality is... (Sartre, 1943: pp. 243)

So according to Sartre the motives may influence me, but if they do not determine my decision and action then those decisions and actions are wholly free. He explains his position with the example of walking along a narrow path near a precipice and without a guard rail:

I at the same moment apprehend these motives as not sufficiently effective. At the very moment when I apprehend my being as horror of the precipice, I am conscious of that horror as not determinate in relation to my possible conduct... If nothing compels me to save my life, nothing prevents me from precipitating myself into the abyss." (Sartre, 1938: pp. 222-223)

Merleau-Ponty likewise viewed free will as always being present. If it exists, it does not magically disappear when influences become strong. On the contrary, those strong influences are what the free will considers. Moreover, even if one does not consciously know or notice those influences, one's decision effectively accepts, rejects, or ignores those influences. One still knows they are making a decision and can choose otherwise. Indeed, if one has free will, it is always present and full-there is no such thing as partial free will, as Merleau Ponty explains:

One cannot be to some extent free, and if, as is often said, motives incline me in a certain direction, one of two things happens: either they are strong enough to force me to act, in which case there is no freedom, or else they are not strong enough, and then freedom is complete, and as great in the worst torments as in the peace of one's home... The alleged motive does not burden my decision; on the contrary my decision lends the motive its force... Our freedom, it is said, is either total or nonexistent. (emphasis added) (Merleau-Ponty, 1945: pp. 278-288)

We see that Merleau-Ponty agrees with Sartre that the situation does not determine the outcome, but rather is what the free will acts upon. He says, "Our freedom does not destroy our situation, but gears itself to it: as long as we are alive, our situation is open, which implies both that it calls up specially favored modes of regulation, and also that it is powerless to bring one into being by itself..." (Merleau-Ponty, 1945: p. 284) 
One of the strongest candidates supporting the position that our free will is oftentimes only partial are addictions-especially drug and alcohol addictions where painful withdrawal symptoms make it particularly hard to stop taking the drug. Certainly the addict has a limited ability to say "no," don't they? This view confuses the difficulty with saying "no" with the ability to say "no." Strong influences, whether they are physical or mental, do not in any way lessen the full possession of the ability to go against those influences. As the late UCLA Professor Rogers Albritton stated, "But strength of will is one thing and freedom of will is another." (Albritton, 1985)

Albritton goes on to explain that many alcoholics do in fact decide to forego one drink, or many drinks. He explains: "It's simply not true, locally, that the alcoholic can't help himself. I mean: he could perfectly well, and sometimes does, empty the bottle into the sink, or the like. But usually he doesn't. He drinks it, in (as far as I can see) full freedom of will... Is there reason to believe about any alcoholic that he literally couldn't stop...?" (Albritton, 1985)

Albritton's position seems to be supported by data on drug addiction which indicates that most people who have tried even the strongest and seemingly most addicting drugs do not ever become addicted, and many of those who do become addicted are able to kick their addiction for long periods of time or permanently. Daniel Shapiro, relying on such research, challenges the standard view that addictions can virtually take away one's ability to say "no" to taking the drug:

An additional problem for the standard view is that most drug users, whether they use legal or illegal drugs, do not become addicts, and few addicts remain so permanently... Three-quarters of Vietnam vets who used heroin in Vietnam became addicted, but after coming home, only half of heroin users in Vietnam continued to use and of those only 12 percent were addicts... Even many heavy cocaine users are able to prevent their use from becoming out of control (or out of control for significant periods of time) by regulating the time and circumstances of use (not during work, never too late at night, limit use on weekdays)... (emphasis added) (Shapiro, 1998, in White 2009: p. 299, 300, 301)

But don't we often act automatically on instinct or habit where we are not making a conscious decision which exercises our free will? This objection seems misplaced because it assumes that we were not conscious of our actual actions and had no ability to overrule them. Although we may not be consciously thinking about our motivations and actions, whether they are instinctual or habitual, we are aware of what we are doing. If we have free will, there is no reason to think that we could not have exercised it to direct our actions in a direction contrary to our instincts or habits. This is the conclusion of Charles Duhigg, a graduate of Harvard Business School who has gone on to be an award winning investigative reporter and writer and who has reviewed the studies on habit. He writes in his best-selling book The Power of Habit as follows: 
As I've tried to demonstrate throughout this book, habits-even once they are rooted in our minds-aren't destiny. We can choose our habits, once we know how. Everything we know about habits, from neurologists studying amnesiacs and organizational experts remaking companies, is that any of them can be changed, if you understand how they function... But every habit, no matter its complexity, is malleable. The most addicted alcoholics can become sober. The most dysfunctional companies can transform themselves. A high school dropout can become a successful manager. However, to modify a habit, you must decide to change. (Duhigg, 2012: p. 270)

Albritton takes the position that absent-minded actions, which are still conscious, are free-will actions:

And even cold sober I sometimes find that I have done quite complicated things "automatically," so to speak, an automatism that is most vivid when it goes awry: What on earth am I doing in the bathroom? Oh, I meant to fetch a certain book from the (adjacent) bedroom, of course. But I have nevertheless gone straight to the bathroom, not in unfreedom of will but in ridiculous absence of mind." (Albritton, 1985)

One might challenge my position by stating that it does not seem that one can resist something that he or she is not aware exists. I think this confuses the limits of our conscious knowledge with a limit on our will. We have a myriad of influences affecting us all the time, and certainly do not notice nor are we conscious of all of them when we make our decisions. However, this point seems irrelevant as to whether when we make our choices or decisions we did so freely.

This objection further mistakes the issue of whether we have the ability to make one choice over another with the issue of whether we are fully to blame for the choices we make when strong and unnoticed influences are disposing us towards making one of the choices. If we have free will, then we certainly have the ability to make a decision in spite of unnoticed or unknown influences, although we may well be less to blame for our ultimate decision when those influences are unnoticed, unconscious, and strong.

Let us take two examples. What if in my hiring practices I have an unconscious bias toward hiring taller people? One might ask how I can resist this? I think that the focus of the question tends to mislead one. Of course I cannot make a conscious decision with the purpose to resist an influence that is unknown to me. However, I am making a decision knowing that I could choose otherwise. Any propensity I have to choose a particular alternative, whether I am consciously aware of the propensity or not, still can be chosen against. I can overrule the option that the propensity is pushing me toward, even if I do not know the source of my leaning toward that option.

Let us take as our second example the following situation: Kathy and Rob have many mutual friends, and have talked to each other at several parties. Kathy is 30 years old, and feels ready to be married and start a family. Kathy finds Rob very appealing. He seems to be intelligent, sensitive, fun-loving, well-traveled, sophis- 
ticated and worldly, interested in bettering the planet, a successful doctor, and one more thing-very attractive. She knows that in many ways he is what she is looking for in a husband. Today Rob asked Kathy to go out on a date. However, there is a very big problem of which Kathy is aware: Rob has told Kathy's friend that he does not want to ever get married or have children. He also finds life more interesting when he changes girlfriends every year or so. Kathy realizes that he is not a potential lifelong mate for her, and she further knows that she does not want to waste time dating someone with whom there is no future. Clearly, she knows that she should resist the many reasons she has for being so drawn to Rob, and say "no" to his request to go out.

But unbeknown to Kathy, there is another subconscious influence motivating her to go out with Rob: Rob is very much like her deceased father. Kathy's father never married her mother, and she was not raised by him, but she did see him on a weekly basis. He was loving and supportive to her, and was a charming, educated, and successful man-similar to Rob. Kathy's father was also not the type to settle down with one woman-again similar to Rob. Now Kathy has not yet consciously noticed the striking similarities between Rob and her dad, nor noticed that Rob in some sense fills a void that she has lived with since her father's death. If she had noticed this, it would probably be much easier to say "no" to Rob's offer to go out on a date, and also on possible future dates with Rob. But she hasn't noticed this unconscious bias toward Rob.

Does this mean that Kathy has only partial free will when she makes her decision of whether to go out with Rob or not? Certainly not. She still has a decision to make, and even though she is not conscious of all of the influences on her that play a role in her ultimate decision, if she has free will then she still has the ability to say "no" to Rob, no matter how strong her subconscious or unconscious favorable bias toward him may be.

It is clear that virtually all of our decisions are made with imperfect knowledge, but this fact does not mean that our free will is only partial. Our lack of knowledge of our subconscious thoughts and motivations is just a part of that imperfect knowledge. Indeed, we do not know all of the facts and circumstances surrounding each of our decisions; we do not know all of the ways in which our choices will affect others and even ourselves; we do not know all of the things that are influencing us when we make our decisions; and lastly, we do not recognize or know our unconscious motives or motivations when making our choices. These facts in no way indicate that our free will is in any way limited.

Now of course, we might not fully blame Kathy for choosing to date Rob if we knew about this unconscious influence, but deserving blame and possessing free will are two different issues. Personally, I am inclined to view the situation as follows: The many things that influence us, no matter how strong they are, do not lessen our free will or relieve us of the responsibility for our choices, but do impact and often mitigate our blameworthiness. After all, if we have free will how can we deny responsibility for our decisions? For instance, your parents might have strongly influenced you, but free will means that you can act con- 
trary to their influences, however difficult that might be. You cannot rightfully thrust responsibility on your parents or anyone else for the decisions you make. You are responsible for those decisions. Nonetheless, strong influences do seem to mitigate the blame and praise we deserve.

The legal system takes just such an approach. If one commits murder, they are responsible and found guilty-even though they may have been negatively influenced by their surroundings, such as by living in a neighborhood proliferated by gangs and drugs, and/or living in a situation which provided them with limited educational and vocational opportunities. ${ }^{19}$ Although criminals are not excused from their responsibility for their actions, in the actual sentencing for their crimes their circumstances will be taken into account, i.e., their sentence will depend on how blameworthy they are found to be. Their upbringing, the situations they have found themselves in, and their experiences will impact their final sentence/punishment.

So if human beings have free will, which I believe they do, then I would place full responsibility on the person making the decision and performing the action and argue that the circumstances or environment do not mitigate that responsibility, while at the same time, however, blameworthiness and praiseworthiness are mitigated and tempered by the internal and outside influences one faces in their life. The influences on our lives do not negate either our free will or our responsibility for our actions, but do impact our assessment of blame or praise since it is certainly difficult to choose to go against strong influences, especially when those influences constitute the views of the great majority of people in your culture, community, and country.

\section{Conclusion}

I have argued that the best explanation for hard choices, which are choices made when there are either incomparable options or equally appealing options, is the presence of free will; and that the two main alternatives, determinism and random choice, do not provide us with a very compelling explanation. In the case of determinism, this is because the reasons supporting either option do not dictate or necessitate that we choose that option, and as such the decision is underdetermined by the reasons for each option. Random choice fares no better since any choice made is supported by reasons and as such is not random at all.

I have further argued that science likely could never prove that we do not have free will since showing that any decision is reflected or caused by our brain neurons firing does not show that the ultimate decision was not arrived at after a

\footnotetext{
${ }^{19}$ Of course, the legal system will relieve one of responsibility if their cognitive abilities are so impaired that they cannot appreciate the wrongfulness of their actions. My discussion on responsibility does not apply to people who have a quite significant degree of mental impairment. Possibly in this situation it is best to say there is no ability to exercise free will and hence they would not have responsibility. Additionally, perhaps in some other cases of a less severe mental disability one could view a person as having a limited free will and therefore limited responsibility. My argument applies to individuals with normal mental faculties where, if you believe in human free will, there can be little doubt that they have it. In such a case, I believe it is best to view their free will as full and not present merely to a degree.
} 
free will consideration of the issues up to the point of a freely willed decision.

Lastly, I have argued that the best way to view free will is as an attribute and ability that is always present, and as such there is no such thing as a partial free will; rather, our decisions come from our free will, and accordingly we are fully responsible for the decisions we make and the actions we take-although external and internal influences, especially those that lurk in our subconscious and of which we are not consciously aware, do mitigate our blameworthiness and praiseworthiness for those decisions.

\section{References}

Albritton, R. (1985). Freedom of Will and Freedom of Action. Presidential Address Delivered before the Fifty-Ninth Annual Pacific Division Meeting of the American Philosophical Association in San Francisco, California. March 22. https://doi.org/10.2307/3131767

Anderson, E. (1993). Value in Ethics and Economics. Cambridge, MA: Harvard University Press.

Balaguer, M. (2004). A Coherent, Naturalistic, and Plausible Formulation of Libertarian Free Will. Nous, 38, 379-406. https://doi.org/10.1111/j.0029-4624.2004.00475.x

Balaguer, M. (2009). Why There Are No Good Arguments for Any Interesting Version of Determinism. Synthese, 168, 1-21. https://doi.org/10.1007/s11229-009-9459-2

Balaguer, M. (2014). Free Will. Cambridge, MA: The MIT Press.

Chang, R. (2012). Are Hard Choices Cases of Incomparability. Philosophical Issues, 22, 106-126. https://doi.org/10.1111/j.1533-6077.2012.00239.x

Chang, R. (2014). Value Incomparability and Incommensurability. In I. Hirose, \& J. Olson (Eds.), The Oxford Handbook of Value Theory. Oxford: Oxford University Press.

Dayan, P., \& Abbott, L. F. (2001). Theoretical Neuroscience. Cambridge, MA: MIT Press.

Duhigg, C. (2012). The Power of Habit. London: Random House Books.

Fried, I., Mukamel, R., \& Kreiman, G. (2011). Internally Generated Preactivation of Single Neurons in Human Medial Frontal Cortex Predicts Volition. Neuron, 69, 548-562. https://doi.org/10.1016/j.neuron.2010.11.045

Gewirth, A. (1978). Reason and Morality. Chicago: University of Chicago Press.

Jarrett, C. (2015). Neuroscience and Free Will Are Rethinking Their Divorce. Science of Us. http://nymag.com/scienceofus/2016/02/a-neuroscience-finding-on-free-will.html\#

Kane, R. (2016). Robert Kane: Reflections on Free Will, Determinism and Indeterminism. The Determinism and Freedom Philosophy Website. http://www.ucl.ac.uk/ uctytho/dfwVariousKane.html

Libet, B. (1983). Time of Conscious Intention to Act in Relation to Cerebral Potential. Brain, 106, 623-642. https://doi.org/10.1093/brain/106.3.623

Mele, A. (2013). Free Will and Neuroscience. Philosophical Exchange, 43, Article 3.

Merleau-Ponty, M. (1945). The Phenomenonology of Peception. Translated by Colin Smith for Routledge, Inc. In Solomon, R. (Ed.), Existentialism (2nd ed.). New York, Oxford: Oxford University Press.

Musser, G. (2015). Is the Cosmos Random? Scientific American, September, 88-93. https://doi.org/10.1038/scientificamerican0915-88

Nahmias, E. (2011). Is Neuroscience the Death of Free Will? In P. Catapano, \& S. Critchley (Eds.), The Stone Reader: Modern Philosophy in 133 Arguments (pp. 330-336). 
New York: Liveright Publishing Corporation, div. of W.W. Norton \& Co.

Nahmias, E. (2015). Why We Have Free Will. Scientific American, January, 77-79.

Phil Papers (2009). http://philpapers.org/surveys

Sartre, J. P. (1938). Nausea. Translated by Lloyd Alexander. New Directions Inc. In R. Solomon (Ed.), Existentialism (2nd ed.). New York, Oxford: Oxford University Press.

Sartre, J. P. (1943). Being and Nothingness. Translated by H. Barnes. Philosophical Library, Inc. In R. Solomon (Ed.), Existentialism (2nd ed.). New York, Oxford: Oxford University Press.

Schultze-Kraft, M. (2015). The Point of No Return in Vetoing Self-Initiated Movements. Proceedings of the National Academy of Sciences of the United States of America, 113, 1080-1085. https://doi.org/10.1073/pnas.1513569112

Shapiro, D. (1998). Addiction and Drug Policy. In J. White (Ed.), Contemporary Moral Problems (9th ed., pp. 298-304). United States: Thomson Wadsworth.

Soon, C., Brass, M., Heinze, H. J., \& Haynes, J. D. (2008). Unconscious Determinants of Free Decisions in the Human Brain. Nature Neuroscience, 11, 543-545. https://doi.org/10.1038/nn.2112

Submit or recommend next manuscript to SCIRP and we will provide best service for you:

Accepting pre-submission inquiries through Email, Facebook, LinkedIn, Twitter, etc. A wide selection of journals (inclusive of 9 subjects, more than 200 journals) Providing 24-hour high-quality service User-friendly online submission system Fair and swift peer-review system Efficient typesetting and proofreading procedure Display of the result of downloads and visits, as well as the number of cited articles Maximum dissemination of your research work

Submit your manuscript at: http://papersubmission.scirp.org/

Or contact ojpp@scirp.org 